\title{
Análise não-paramétrica da sanidade de sementes e índices de eliminação e classificação de genótipos de soja
}

\author{
Edmar Soares de Vasconcelos ${ }^{(1)}$, Múcio Silva Reis(1), Tuneo Sedyiama( ${ }^{(2)}$ e Cosme Damião Cruz ${ }^{(2)}$
}

\begin{abstract}
(1)Universidade Federal de Viçosa (UFV), Departamento de Fitotecnia, Avenida P.H. Rolfs, s/no, Campus Universitário, CEP $36571-000$ Viçosa, MG. E-mail: vasconceloses@yahoo.com.br, msreis@ufv.br (2)UFV, Departamento de Biologia Geral. E-mail: tuneo@ufv.br, cdcruz@ufv.br
\end{abstract}

Resumo - O objetivo deste trabalho foi avaliar genótipos de soja quanto à sanidade de semente, com um método de análise, pelo qual se obtém índices de sanidade (eliminação e classificação) com base em análise não-paramétrica. Esses índices consistiram em eliminar os genótipos com incidência de patógenos acima de um dado valor, estabelecido pelo experimentador e, em seguida, classificar os genótipos não eliminados, por ordem de incidência desses patógenos. A fim de comprovar sua eficácia, realizaram-se a simulação e comparação desse método com outros, e seu uso em dados de germinação e sanidade das sementes de cultivares e linhagens de soja, de ensaios finais do Programa de Melhoramento de Soja, do Departamento de Fitotecnia, da Universidade Federal de Viçosa, conduzidos no ano agrícola de 2002/2003. Os pesos das variáveis e os limites de corte, utilizados nos índices, foram estabelecidos tendo-se levado em consideração estudos que relacionam a sanidade das sementes e sua germinação. A utilização dos índices propostos permite classificar genótipos de soja, quanto à qualidade sanitária das sementes, e eliminar das análises os genótipos que não atingiram os níveis mínimos requeridos.

Termos para indexação: Glycine max, índice de seleção, qualidade de semente.

\section{Non-parametric analysis of seed sanity and elimination and ranking indices of soybean genotypes}

\begin{abstract}
The objective of this work was to assess soybean genotypes for seed sanity, with a method by which a sanity index (elimination and classification) is obtained based on non-parametric analysis. This index consisted in the elimination of genotypes with pathogen incidence above a certain value, established by the researcher, and then the classification of the noneliminated genotypes in the first step, ordering them according to the incidence of the pathogens. To verify its effectiveness, it was accomplished a simulation study and comparison of this proposed method with others, and its use in germination and sanity data of seeds from soybean lineages and cultivars of final experiments of the Soybean Breeding Program of Departmento de Fitotecnia, Universidade Federal de Viçosa, in 2002/2003 crop season. The weights of the variables and the cut limits used in the index were established considering studies related to seeds sanity and their germinations. The use of the proposed index allows the ranking of soybean genotypes, regarding to the sanitary quality of the seeds, and the elimination from the analyses of the genotypes that have not reached the requested minimum levels.
\end{abstract}

Index terms: Glycine max, selection index, seed physiological quality.

\section{Introdução}

A semente é o produto final originado de uma série de processos, que incluem melhoramento genético, produção, colheita, beneficiamento, secagem, armazenamento, análise, controle e semeadura e, no decorrer de alguns desses processos, a semente fica sujeita à deterioração. Em regiões tropicais, por exemplo, é comum a ocorrência de condições climáticas desfavoráveis, durante a fase final de maturação da soja. Freqüentemente, o excesso de chuvas associado à ocorrência de altas temperaturas, nessa fase, ocasiona sérios danos à produção de sementes, pois gera altos índices de infecção, causada principalmente por fungos que estão associados à baixa qualidade fisiológica das sementes (Pereira et al., 2000; Costa et al., 2003).

A ocorrência de doenças é um fator limitante à obtenção de qualidade e alto rendimento na produção 
de grãos de soja (Machado et al., 2001). A expansão da cultura de soja, na Região Central do Brasil, e a falta de tratamento químico das sementes propiciaram o aparecimento de inúmeras doenças, antes consideradas de menor importância (Yorinori et al., 1993). Muitos fitopatógenos, na maioria fungos, podem estar associados às sementes, pois afetam sua germinação, o vigor das plântulas e acarretam reduções na emergência e na produtividade (Patrício et al., 1991; Sinclair, 1991; Bringel et al., 2001; Hamawaki et al., 2002).

Dentre os vários fungos transportados pelas sementes de soja, que são responsáveis por sua baixa qualidade, destacam-se: Phomopsis spp., causador da seca-dahaste e seca-da-vagem, além do apodrecimento das sementes; Colletotrichum dematium, que causa antracnose; Cercospora kikuchii, causador do crestamento foliar e mancha-púrpura-da-semente; e Fusarium sp., associado a podridões de sementes (Sinclair, 1982). Além desses fitopatógenos, alguns fungos considerados de armazenamento, como Aspergillus sp. e Penicillium spp., podem provocar a deterioração de sementes que possuem alto teor de água ou são armazenadas em ambiente com umidade relativa elevada (Menten, 1991; Lacerda et al., 2003).

Atualmente, os métodos mais utilizados na seleção de genótipos de soja para a sanidade das sementes são subjetivos e se realizam por meio de avaliações de incidência de patógenos nas sementes ou nas plantas (Hamawaki et al., 2002), sendo necessário estabelecerem-se critérios e procedimentos, para facilitar a interpretação das análises de sanidade das sementes. Assim, é preferível usar métodos que não exijam a distribuição normal dos dados e que sejam simples, pois dados da percentagem de sementes infectadas por patógenos dificilmente apresentam normalidade.

Na elaboração de índices de seleção, Williams (1962) sugeriu ponderar valores fenotípicos pelos seus respectivos pesos econômicos. Outros índices (Elston, 1963; Mulamba \& Mock, 1978) identificam-se por não exigirem o estabelecimento desses pesos econômicos. Ainda, pode-se fazer uso dos índices de Schwarzbach, conforme apresentado por Wricke \& Weber (1986), de Garcia (1998) ou de Pizzinato et al. (2000), na avaliação da qualidade sanitária das sementes.

O objetivo deste trabalho foi avaliar genótipos de soja, quanto à sanidade de semente, propondo-se um método de análise, por meio do qual se obtém índices de sanidade (eliminação e classificação) com base em análise não-paramétrica.

\section{Material e Métodos}

$\mathrm{Na}$ elaboração dos índices de eliminação e classificação, foram aplicadas as técnicas de análise nãoparamétrica (as quais permitem análise de dados, sem exigência do conhecimento da distribuição deles), para a seleção simultânea de caracteres, de forma a se estabelecer um índice que leve em consideração uma série de atributos favoráveis que, de alguma forma, confiram rendimento comparativamente superior a um dado genótipo, conforme definição de índice de seleção apresentado por Cruz \& Carneiro (2006).

Os índices de eliminação e classificação, no primeiro passo, consistiram em eliminar os genótipos com incidência de patógenos acima de um limite de corte, estabelecido pelo experimentador, e variou, assim, o grau de rigor. No segundo passo, realizou-se a classificação dos genótipos não eliminados no primeiro passo; essa classificação foi realizada com base nas diferentes características, avaliadas em teste de sanidade de sementes (exemplo: Phomopsis spp., C. kikuchii, entre outras), as quais são importantes na seleção dos genótipos de melhor sanidade.

No processo de eliminação dos genótipos, utilizou-se o índice de seleção estabelecido por Elston (1963), conhecido também como índice livre de pesos e parâmetros, expresso por:

$I_{e}=\prod_{i=1}^{n}\left(K_{i}-X_{i}\right)=\left(K_{1}-X_{1}\right)\left(K_{2}-X_{2}\right) \ldots\left(K_{n}-X_{n}\right)$,

em que: $\mathrm{I}_{\mathrm{e}}$ é o valor do índice de Elston para o genótipo considerado que, nesse caso, foi utilizado como índice de corte de genótipos, quando a incidência de patógenos foi acima do limite de corte estabelecido; $\mathrm{X}_{\mathrm{i}}$ é o valor fenotípico do i-ésimo caráter, observado no teste de sanidade; e $\mathrm{K}_{\mathrm{i}}$ é o limite de corte do i-ésimo caráter, ou seja, o valor máximo estabelecido pelo experimentador, para cada patógeno em estudo, acima do qual os genótipos são eliminados.

Se $\mathrm{K}_{\mathrm{i}}<\mathrm{X}_{\mathrm{i}}$ para qualquer uma das características avaliadas, então $\left(\mathrm{K}_{\mathrm{i}}-\mathrm{X}_{\mathrm{i}}\right)=0$ e, conseqüentemente, os genótipos serão eliminados, pois $\mathrm{I}_{\mathrm{e}}=0 \mathrm{em}$ razão da natureza multiplicativa do índice.

O segundo passo correspondeu à elaboração do índice de classificação, em que foi utilizado o índice de seleção desenvolvido por Mulamba \& Mock (1978), e que se baseia na classificação dos genótipos, em relação a cada uma das características analisadas. A classificação dos genótipos foi realizada na ordem favorável à seleção, de forma que o melhor genótipo ocupou o primeiro lugar 
e os demais ficaram em sequiência. Nos casos em que ocorreram valores fenotípicos de mesma magnitude, o procedimento para atribuição dos valores relativos à classificação exigiu a determinação da posição média entre os genótipos, e essa posição foi atribuída aos genótipos de mesmos valores fenotípicos.

Inúmeros fatores podem influenciar na decisão do peso estabelecido para cada patógeno. Assim, não se fixou valor de corte para esses patógenos, pois sua definição pode variar de acordo com o uso das sementes ou objetivos do melhorista.

O índice de Mulamba \& Mock (1978) é obtido, somando-se os "ranks" ou classificações, conforme a expressão: $\mathrm{I}_{\mathrm{m}}=\Sigma \mathrm{r}_{\mathrm{ij}}$, em que $\mathrm{I}_{\mathrm{m}}$ é o índice e $\mathrm{r}_{\mathrm{ij}}$ é o número de classificação do genótipo i para a variável j.

Na elaboração do índice de classificação, entretanto, acrescentou-se ao índice de Mulamba \& Mock (1978) um peso econômico para cada característica avaliada. Isto é importante, pois cada patógeno propicia efeitos diferentes na qualidade da semente; alguns podem inutilizá-la, impedindo sua germinação ou a emergência das plântulas, como é o caso de Phomopsis sp.; outros podem causar danos apenas em plantas já desenvolvidas, sem afetar a germinação das sementes, como é o caso de C. kikuchii (Galli et al., 2005).

A dedução da fórmula para o índice de classificação foi realizada de forma a permitir que o resultado fosse expresso em percentagem da qualidade sanitária de um ideótipo, tendo-se obtido a seguinte fórmula: $\mathrm{I}_{\mathrm{s}}=100\left[100-\Sigma\left(\mathrm{p}_{\mathrm{j}} \mathrm{r}_{\mathrm{ij}} / 100\right)\right] /\left[100-\Sigma\left(\mathrm{p}_{\mathrm{j}} \mathrm{r}_{\mathrm{Ij}} / 100\right)\right]$, em que: $I_{s}$ é o índice de classificação; $p_{j}$ é o peso econômico atribuído à característica $\mathrm{j} ; \mathrm{r}_{\mathrm{ij}}$ é o número da classificação do genótipo i para a característica j; e $\mathrm{r}_{\mathrm{Ij}}$ é o número da classificação do ideótipo (I) para a característica j.

Os genótipos eliminados no primeiro passo não foram incluídos no segundo, e receberam o valor zero no índice de eliminação. O resultado final do índice de eliminação (primeiro passo) e do índice de classificação (segundo passo) gerou os índices de eliminação e classificação. Também foi necessária a elaboração de um ideótipo para cada local ou ambiente, uma vez que a classificação e atribuição dos valores de "rank" aos genótipos foi realizada para cada característica avaliada, em cada ambiente, e os valores foram expressos em percentagem do ideótipo. Ideótipo é definido como o genótipo que possui o valor ideal para cada uma das características avaliadas; em nosso caso é o que não é infectado por fungos e tem zero de infecção em relação a todos os patógenos (Tabela 1).

A fim de se comprovar a eficácia do método, foram simulados valores de sanidade, em percentagem de incidência, para dez genótipos de soja, de forma a se obter uma seqüência decrescente na qualidade sanitária de suas sementes. Para tanto, consideraram-se sete características iniciais: Alternaria sp., Aspergillus sp., Chaetomium sp., Cercospora kikuchii, Colletotrichum dematium, Fusarium spp. e Phomopsis spp., e uma oitava que correspondeu ao somatório das sete anteriores (total de fungos). Na Tabela 1, são apresentados os

Tabela 1. Valores fenotípicos de incidência de doenças, pesos econômicos e limite de corte, estipulados para oito características simuladas, utilizados para a comprovação da eficiência dos índices de eliminação e classificação.

\begin{tabular}{|c|c|c|c|c|c|c|c|c|}
\hline \multirow[t]{2}{*}{ Genótipo } & \multicolumn{8}{|c|}{ Características simuladas $^{(1)}$} \\
\hline & I & II & III & IV & $\mathrm{V}$ & VI & VII & VIII \\
\hline 1 & 0,0 & 0,0 & 0,0 & 0,0 & 0,0 & 0,0 & 0,0 & 0,0 \\
\hline 2 & 6,5 & 0,0 & 0,0 & 0,0 & 0,0 & 0,0 & 0,0 & 6,5 \\
\hline 3 & 6,5 & 6,5 & 0,0 & 0,0 & 0,0 & 0,0 & 0,0 & 13,0 \\
\hline 4 & 6,5 & 6,5 & 6,5 & 0,0 & 0,0 & 0,0 & 0,0 & 19,5 \\
\hline 5 & 6,5 & 6,5 & 6,5 & 6,5 & 0,0 & 0,0 & 0,0 & 26,0 \\
\hline 6 & 6,5 & 6,5 & 6,5 & 6,5 & 6,5 & 0,0 & 0,0 & 32,5 \\
\hline 7 & 6,5 & 6,5 & 6,5 & 6,5 & 6,5 & 6,5 & 0,0 & 39,0 \\
\hline 8 & 6,5 & 6,5 & 6,5 & 6,5 & 7,5 & 7,5 & 7,5 & 48,5 \\
\hline 9 & 0,0 & 0,0 & 0,0 & 0,0 & 0,0 & 0,0 & 28 & 28,0 \\
\hline 10 & 0,0 & 0,0 & 0,0 & 0,0 & 0,0 & 25,0 & 26,0 & 51,0 \\
\hline Peso econômico & 1,0 & 3,0 & 2,0 & 2,0 & 12,0 & 80,0 & 80,0 & 170,0 \\
\hline Limite de corte ${ }^{(2)}$ & 100,0 & 100,0 & 100,0 & 100,0 & 20,0 & 20,0 & 25,0 & 47,3 \\
\hline Referência & $-(3)$ & - & - & Galli et al. (2005) & Galli et al. (2005) & - & Ellis et al. (1974) & Passos (1994) \\
\hline
\end{tabular}

(1)I: Alternaria sp.; II: Aspergillus sp.; III: Chaetomium sp.; IV: Cercospora kikuchii; V: Colletotrichum dematium; VI: Fusarium spp.; VII: Phomopsis spp.; VIII: total de fungos. ${ }^{(2)} \mathrm{O}$ limite de corte igual a 100 indica que não se tem estabelecido um limite de corte com base na germinação da semente, quanto à presença de determinado patógeno. ${ }^{(3)}$ Sem referência. 
valores fenotípicos estipulados, além dos pesos econômicos e o limite de corte utilizados nas avaliações.

Os pesos econômicos, utilizados na elaboração do índice de classificação, corresponderam aos resultados da covariância observada entre os valores das variáveis Alternaria sp., Aspergillus sp., Chaetomium sp., C. kikuchii; C. dematium, Fusarium spp., Phomopsis spp. e total de fungos (sanidade das sementes), com suas respectivas percentagens de germinação das sementes; os resultados do teste de germinação foram apresentados para sementes da mesma amostra.

No estabelecimento de tais covariâncias, foram avaliados experimentos, em outro trabalho, relativos a dois anos agrícolas (2000/2001 e 2002/2003), com 17 genótipos em cinco locais, no primeiro ano, e 40 genótipos em quatro locais, no segundo ano, o que originou covariância entre 245 pares de observações (Vasconcelos, 2006).

Foram utilizados dados, disponíveis na literatura, sobre incidência de sementes de soja infectadas pelos patógenos, na determinação dos limites de corte: de $20 \%$ para C. dematium e $100 \%$ para C. kikuchii (Galli et al., 2005); de 25\% para Phomopsis spp. (Ellis et al., 1974); e de $47,3 \%$ para o total de fungos (Passos, 1994). Para os demais fungos, não foram encontrados relatos na literatura, a respeito da incidência de sementes infectadas pelos patógenos, nem sobre os prejuízos causados por eles à qualidade fisiológica das sementes, considerandose o limite de corte igual a 100\% (ou sem limite de corte). Para Fusarium spp., foi considerado 20\% como nível máximo de infecção (limite de corte de 20\%).

Vale ressaltar que, para cada trabalho com finalidades diferentes, devem-se adotar limites de corte que satisfaçam às exigências de análise, tendo-se ou não maior restrição.

$\mathrm{Na}$ avaliação dos dados apresentados na Tabela 1, foram aplicados os seguintes métodos: índice de seleção de Willians ou índice-base; índice de seleção de Elston (1963) ou índice livre de pesos e parâmetros; índice de seleção de Mulamba \& Mock (1978); índice de seleção proposto por Schwarzbach, citado por Wricke \& Weber (1986); índice de seleção de Garcia (1998); índice de sanidade de Pizzinato et al. (2000); e índices de eliminação e classificação, proposto neste trabalho.

No índice proposto por Garcia (1998), foram obtidos os recíprocos por $1\left(\mathrm{P}_{\mathrm{i}}+0,5\right)$, uma vez que se atribuem valores de médias iguais a zero, em uma ou mais características para alguns dos genótipos, o que facilmente pode ser observado na prática.
Pizzinato et al. (2000) desenvolveram, em 1994, um método para a estimação de um índice de sanidade, a fim de facilitar a comparação entre diferentes tratamentos químicos de sementes de pupunheira. Esse índice envolveu a média das respostas dos tratamentos fungicidas de cada fungo, em relação ao tratamento sem controle químico. Na utilização deste método, o tratamento testemunha correspondeu ao maior valor estipulado para cada característica avaliada.

Para exemplificar a utilização dos índices propostos, avaliou-se um experimento com testes de germinação e sanidade de sementes de cultivares e linhagens de soja, de ciclo de maturação tardio, provenientes dos ensaios finais de avaliação do comportamento agronômico, do Programa de Melhoramento de Soja, do Departamento de Fitotecnia da Universidade Federal de Viçosa, conduzidos em Minas Gerais, no ano agrícola de 2002/ 2003.

Os materiais foram avaliados em quatro diferentes ambientes: Capinópolis 1 (solo fértil, $300 \mathrm{~kg} \mathrm{ha}^{-1} \mathrm{de}$ 0-25-25 como adubação de base); Capinópolis 2 (solo pobre, sem adubação de base); Tupaciguara e Florestal. Em cada ensaio de campo, utilizou-se o delineamento experimental de blocos ao acaso, com três repetições. A parcela foi constituída de quatro linhas distanciadas $0,5 \mathrm{~m}$ entre si, com $5 \mathrm{~m}$ de comprimento. As sementes foram coletadas em área útil de $4 \mathrm{~m}^{2}$, nas duas linhas centrais, com $4 \mathrm{~m}$ de comprimento.

Foram avaliadas as quatro cultivares e as 16 linhagens, listadas a seguir, nos quatro locais: DM 339; BRS - Celeste; Conquista; UFV18 - Patos de Minas; UFV98 - 267F10RC1,3; UFV98 - 1640CRR73; UFV99 -CRR768; UFV98 - 878565; UFV98 - 6011099; UFV99 - CRR7701; UFV01 - 823278B; UFV01 - 823281B; UFV99 - 651214; UFV90 - 8552042; UFV99 - 828393; UFV01 - 606207B; UFV01 - 875386B; UFV01 878397B; UFV99 - 9331958 e UFV99 - 954206B.

O teste de germinação (TG) foi realizado de acordo com os critérios estabelecidos pelas Regras para Análise de Sementes (Brasil, 1992). Os resultados foram expressos em percentagem média de plântulas normais. A qualidade sanitária das sementes foi avaliada por meio do "Blotter Test" ou teste do papel-filtro, conforme as Regras para Análise de Sementes (Brasil, 1992). Os resultados foram expressos em percentagem de sementes infectadas por fungos.

Os diferentes índices, obtidos por meio de diferentes métodos análise, foram avaliados, tendo-se ordenando 
os genótipos e utilizado o método de correlação classificatória de Spearman.

\section{Resultados e Discussão}

Na análise da classificação dos genótipos, o método de seleção de Willians (1962), falhou apenas na classificação do genótipo 9 , o qual foi simulado a fim de se representar genótipos com alta incidência de Phomopsis spp. (Tabela 2). Esse método não foi capaz de identificar o problema e eliminar esse genótipo, uma vez que apresentou incidência do patógeno (Phomopsis sp.) acima do limite de corte estabelecido (Tabela 1).

Verificou-se excelente classificação dos genótipos pelo método de Elston (1963), assim como pelo método proposto neste trabalho. Entretanto, a escala em que os dados são apresentados, no método de Elston, não foi indicativa, ou seja, os resultados obtidos não possuem um ponto de referência ou de comparação, o valor de cada material não se encontra como uma percentagem do valor de qualidade do ideótipo (genótipo 1). O método de Pizzinatto et al. (2000) gerou classificação distinta da esperada (ideal). Esse método não excluiu da análise os genótipos que possuíam incidência de fungos acima dos limites estabelecidos.

Ao se analisarem os dados simulados pelos índices de Schwarzbach, Mulamba \& Mock (1978) e pelo índice de seleção de Garcia (1998), verificou-se que levaram ao mesmo erro apresentado pelo índice de seleção de Willians (1962); o genótipo 9 não foi eliminado, porque apresentou incidência de Phomopsis acima do limite de corte estabelecido (Tabela 2).

A comparação entre os métodos foi realizada com base no teste de correlação de Spearman, tendo-se obtido as correlações de todos os métodos em relação ao ideal. Os resultados das correlações foram: $\mathrm{r}_{\text {ideal } \mathrm{x} \text { Willians }}=-0,9636 ; \quad \mathrm{r}_{\text {ideal }} \times$ Elston $=1,0000$; $r_{\text {ideal } x \text { Schuwarzbach }}=-0,9636 ; r_{\text {ideal } x \text { Mulamba e Mock }}=-0,9636$; $\mathrm{r}_{\text {ideal } \times \text { Pizzinatto }}=0,5030 ; \mathrm{r}_{\text {ideal } \times \text { Garcia }}=-0,9394 \mathrm{e}$ $\mathrm{r}_{\text {ideal } \mathrm{x} \text { Proposto }}=1,0000$.

De acordo com os resultados da correlação de Spearman, que se baseia na classificação dos dados e não em sua variância, os índices utilizados, de maneira geral, apresentaram classificações que se relacionam à ideal, com exceção do índice proposto por Pizzinatto et al. (2000). Entretanto, apenas os índices propostos neste trabalho e o índice de Elston condizem com a classificação esperada, com correlação igual a 1 , o que significa que todos os genótipos foram classificados de acordo com o esperado ou de acordo com o ideal. Essa proximidade já era esperada, visto que os índices propostos são uma derivação do índice de Elston.

Em consequiência da ausência de fungos, em alguns materiais, e da falta de normalidade dos dados de sanidade das sementes, não foi possível realizar a análise de variância nos dados da incidência de fungos, nas sementes de soja avaliadas nos quatro experimentos, tendo sido realizada apenas uma análise descritiva quanto ao uso dos índices de eliminação e classificação. Alguns autores, como Banzatto \& Kronka (2006) e Hamawaki et al. (2002), realizaram a transformação dos dados, contudo, neste trabalho, a transformação de dados não propiciou normalidade dos mesmos.

De acordo com a análise descritiva dos dados, a média da incidência de Phomopsis spp. foi superior àquela de incidência dos demais fungos (Tabela 3). Esse resultado foi semelhante ao obtido por Costa et al. (2003), que avaliaram sementes oriundas do Rio Grande do Sul, Paraná, Minas Gerais e Goiás.

Tabela 2. Resultados proporcionados pelos diferentes métodos de análise, utilizados nos dados simulados para se verificar a eficiência dos índices propostos.

\begin{tabular}{|c|c|c|c|c|c|c|c|c|}
\hline \multirow[t]{2}{*}{ Genótipo } & \multirow[t]{2}{*}{ Classificação ideal $^{(1)}$} & \multicolumn{7}{|c|}{ Índices } \\
\hline & & $\begin{array}{l}\text { Willians } \\
(1962)\end{array}$ & $\begin{array}{l}\text { Elston } \\
(1963)\end{array}$ & Schwarzbach $^{(2)}$ & $\begin{array}{c}\text { Mulamba \& Mock } \\
(1978)\end{array}$ & $\begin{array}{l}\text { Pizzinato et al. } \\
(2000)\end{array}$ & Garcia (1998) & Proposto \\
\hline 1 & 10,0 & 0,00 & 0,45 & 0,00 & 8,81 & 100,00 & 0,00 & 100,00 \\
\hline 2 & 9,0 & 11,12 & 0,36 & 9,19 & 10,56 & 85,91 & 39,22 & 98,11 \\
\hline 3 & 8,0 & 22,36 & 0,28 & 15,92 & 12,41 & 71,81 & 40,81 & 96,14 \\
\hline 4 & 7,0 & 33,54 & 0,21 & 22,52 & 14,21 & 59,39 & 41,40 & 94,22 \\
\hline 5 & 6,0 & 44,72 & 0,15 & 29,07 & 16,01 & 45,29 & 41,74 & 92,29 \\
\hline 6 & 5,0 & 56,55 & 0,06 & 35,60 & 20,01 & 31,20 & 42,51 & 89,98 \\
\hline 7 & 4,0 & 72,80 & 0,02 & 42,12 & 25,31 & 26,36 & 46,30 & 85,08 \\
\hline 8 & $0,0^{(3)}$ & 95,77 & 0,00 & 51,87 & 30,21 & 18,51 & 49,81 & 0,00 \\
\hline 9 & 0,0 & 70,00 & 0,00 & 39,60 & 22,11 & 80,64 & 45,51 & 0,00 \\
\hline 10 & 0,0 & 127,50 & 0,00 & 62,47 & 32,81 & 63,39 & 49,63 & 0,00 \\
\hline
\end{tabular}

${ }^{(1)}$ Classificação ideal dos genótipos, estabelecida para diferenciar a qualidade dos genótipos simulados; a maior classificação corresponde à menor incidência de doenças. ${ }^{(2)}$ Schwarzbach, citado por Wricke \& Weber (1986). ${ }^{(3)}$ Genótipos que deveriam ser eliminados das análises, por apresentar incidência de fungos acima dos limites de corte. 
Com relação ao limite superior da variação, verificouse que algumas observações foram superiores ao nível crítico para Fusarium sp., Phomopsis sp. e total de fungos (20, 25 e 47,3\%, respectivamente). Valores próximos e de maior magnitude que esses também foram obtidos por Hamawaki et al. (2002), que avaliaram sementes de genótipos de soja de ciclo precoce e médio em Uberlândia, MG.

De acordo com os resultados dos índices de sanidade, a linhagem UFV01 - 823281B apresentou o maior índice e, entre os ambientes, baixo desvio-padrão do índice, o que indica, que o comportamento deste genótipo foi mais homogêneo nos diferentes locais de avaliação (Tabela 4). A linhagem UFV01 - 823278B apresentou os segundos maiores índices de eliminação e classificação, entretanto, apresentou desvio-padrão com maior magnitude em

Tabela 3. Média, variância e amplitude de variação da incidência média de diferentes patógenos nas sementes de genótipos de soja de ciclo tardio, colhidas em Capinópolis 1 e 2, Tupaciguara e Florestal, MG, no ano agrícola de 2002/2003.

\begin{tabular}{lccc}
\hline Fungo & Média (\%) & Variância & Amplitude (\%) \\
\hline Alternaria sp. & 0,073 & 0,169 & $0-4$ \\
Aspergillus sp. & 0,407 & 1,827 & $0-14$ \\
Cercospora kikuchii & 0,560 & 3,164 & $0-16$ \\
Chaetomium sp. & 0,193 & 0,591 & $0-6$ \\
Colletotrichum dematium & 0,220 & 0,527 & $0-4$ \\
Phomopsis spp. & 6,167 & 98,714 & $0-48$ \\
Fusarium sp. & 4,327 & 78,810 & $0-44$ \\
\hline Total de fungos & 12,000 & 387,452 & $0-76$ \\
\hline
\end{tabular}

relação aos demais genótipos, pelo seu valor de índices de apenas 59,51\%, em Florestal, enquanto nos outros ambientes ficou acima de $88 \%$. Os genótipos UFV99 828393 e UFV98 - 878565 apresentaram valores de índices superiores à média geral, apesar dos desviospadrão elevados, também ocasionados pelo comportamento em Florestal.

Os genótipos DM 339, UFV98 - 267F10RC1,3, UFV98 - 1640CRR73, UFV99 - 651214, UFV01 875386B, UFV01 - 878397B, UFV99 - 9331958 , UFV99 - 954206B, BRS - Celeste, UFV18 Patos de Minas e UFV01 - 606207B apresentaram valores iguais a zero pelo índice de corte (Tabela 4), e foram, então, eliminados no primeiro passo do processo de obtenção dos índices de eliminação e classificação.

Os valores iguais a zero, para os índices de eliminação e classificação (Tabela 4), foram originados pela análise em Tupaciguara. Nesse local, poucos materiais se destacaram, ou seja, apresentaram menor infecção pelos diferentes patógenos avaliados. Esse resultado pode ter ocorrido em razão do excesso de chuvas, associado à ocorrência de altas temperaturas, na colheita, o que ocasiona sérios danos à produção de sementes e gera altos índices de infecção (Costa, 1984).

Os valores médios de incidência de $C$. kikuchii e Fusarium spp. dos quatro ambientes (Tabela 5) foram próximos aos obtidos por Pereira et al. (2000), que

Tabela 4. Índices de sanidade obtidos para as sementes de genótipos de soja de ciclo tardio, colhidas em Capinópolis 1 e 2 , Tupaciguara e Florestal, no ano agrícola de 2002/2003.

\begin{tabular}{|c|c|c|c|c|c|c|}
\hline \multirow[t]{2}{*}{ Genótipo } & \multicolumn{4}{|c|}{ Percentagem do ideótipo para cada local } & \multirow[t]{2}{*}{ Média } & \multirow[t]{2}{*}{ Desvio-padrão } \\
\hline & Capinópolis 1 & Capinópolis 2 & Tupaciguara & Florestal & & \\
\hline Ideótipo & 100,00 & 100,00 & 100,00 & 100,00 & 100,00 & 0,00 \\
\hline DM 339 & 69,08 & 43,25 & $-(1)$ & 86,60 & - & - \\
\hline BRS - Celeste & 38,35 & 48,88 & - & 37,85 & - & - \\
\hline Conquista & 88,47 & 62,05 & 68,53 & 59,28 & 69,58 & 13,18 \\
\hline UFV18 Patos de Minas & 45,98 & 50,74 & - & 86,60 & - & - \\
\hline UFV $98-267 F 10 R C 1,3$ & 55,07 & 100,00 & - & 70,43 & - & - \\
\hline UFV98 - 1640CRR73 & 62,24 & 82,61 & - & 86,60 & - & - \\
\hline UFV99 - CRR768 & 52,66 & 73,29 & 74,08 & 50,04 & 62,52 & 12,94 \\
\hline UFV98 - 878565 & 63,41 & 92,27 & 80,57 & 67,95 & 76,05 & 13,02 \\
\hline UFV98 - 6011099 & 30,72 & 48,04 & 95,11 & 53,74 & 56,90 & 27,29 \\
\hline UFV99 - CRR7701 & 42,68 & 82,61 & 72,13 & 83,84 & 70,31 & 19,16 \\
\hline UFV01 - 823278B & 88,47 & 100,00 & 90,52 & 59,51 & 84,63 & 17,48 \\
\hline UFV01 - 823281B & 88,60 & 77,92 & 86,87 & 100,00 & 88,35 & 9,07 \\
\hline UFV99 - 651214 & 59,62 & 69,43 & - & 78,40 & - & - \\
\hline UFV90 - 8552042 & 73,98 & 73,29 & 78,83 & 67,95 & 73,51 & 4,46 \\
\hline UFV99 - 828393 & 96,46 & 73,64 & 92,15 & 43,91 & 76,54 & 23,90 \\
\hline UFV01 - 606207B & 47,54 & 50,74 & - & 33,34 & - & - \\
\hline UFV01 - 875386B & 31,55 & 65,09 & - & 52,63 & - & - \\
\hline UFV01 - 878397B & 90,10 & 81,47 & - & 100,00 & - & - \\
\hline UFV99 - 9331958 & 83,69 & 77,92 & - & 86,60 & - & - \\
\hline UFV99 - 954206B & 76,09 & 59,59 & - & 86,60 & - & - \\
\hline Média & 65,94 & 72,04 & 78,65 & 71,04 & 70,33 & 5,22 \\
\hline
\end{tabular}

${ }^{(1)}$ Genótipos eliminados no primeiro passo dos índices de eliminação e classificação. 


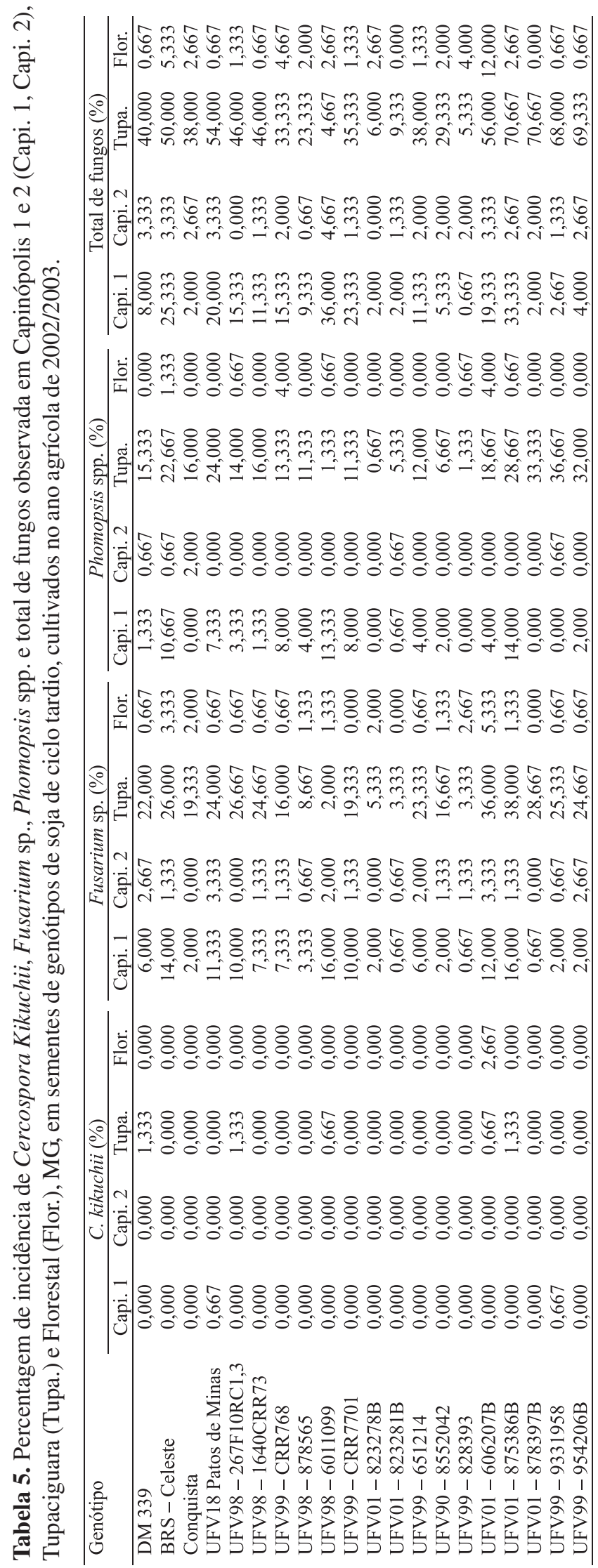

avaliaram sete cultivares precoces de soja, produzidas em três épocas de semeadura.

A realização de seleção de genótipos com base apenas na característica de incidência de $C$. kikuchii pode não ser uma boa estratégia, uma vez que ocorreu problema de incidência de outros fungos no material selecionado; por exemplo, o genótipo BRS - Celeste que não apresentou incidência de $C$. kikuchii seria selecionado. Contudo, esse genótipo apresentou $26 \%$ de incidência de Fusarium spp., em Tupaciguara (Tabela 5), e por isso deveria ser eliminado da análise.

Na seleção de genótipos, com base na incidência de Phomopsis spp. (Tabela 5), as linhagens UFV01 823278B e UFV99 - 828393 foram selecionadas. A seleção com base no total de fungos (Tabela 5) propiciou a escolha das linhagens UFV01 - 823278B, UFV01 - 823281B e UFV99 - 828393; a seleção por essas variáveis foi suficiente, para esse caso, uma vez que se trata de linhagens cujas sementes apresentaram menor incidência de fungos.

Com relação às diferentes estratégias de seleção, apresentadas acima (com base na incidência de C. kikuchii, ou Phomopsis spp., ou ainda total de fungos), a seleção proposta neste trabalho gerou melhores resultados, uma vez que os índices levaram em consideração todas essas variáveis em conjunto. Uma vantagem na utilização dos índices de eliminação e classificação é a classificação dos genótipos por um índice final, o que facilitou a interpretação do resultado, além da eliminação prévia dos genótipos indesejados.

\section{Conclusão}

A utilização dos índices de eliminação e classificação permite classificar os genótipos de soja, quanto à qualidade sanitária das sementes, e eliminar das análises os genótipos que não atingem os níveis mínimos requeridos.

\section{Referências}

BANZATTO, D.A.; KRONKA, S.N. Experimentação agrícola. 4.ed. Jaboticabal: Funep, 2006. 237p.

BRASIL. Ministério da Agricultura. Regras para a análise de sementes. Brasília: SNDA: DNDV: CLAV, 1992. 365p.

BRINGEL, J.M.M.; MORAES, M.H.D.; MENTEN, J.O.M.; BEDENDO, I.P. Qualidade sanitária e fisiológica de sementes de soja produzidas na região de Balsa, Maranhão. Summa Phytopathologica, v.27, p.438-441, 2001. 
COSTA, A.V. Avaliação da qualidade fisiológica da semente de soja (Glycine max (L.) Merrill), produzidas em cinco localidades do Estado de Minas Gerais. 1984. 146p. Tese (Doutorado) - Universidade Federal de Viçosa, Viçosa.

COSTA, N.P.; MESQUITA, C. de M.; MAURINA, A.C.; FRANÇA-NETO, J.B.; KRZYZANOWSKI, F.C.; HENNING, A.A. Qualidade fisiológica, física e sanitária de sementes de soja produzidas no Brasil. Revista Brasileira de Sementes, v.25, p.128-132, 2003.

CRUZ, C.D.; CARNEIRO, P.C.S. Modelos biométricos aplicados ao melhoramento genético. 2.ed. Viçosa: UFV, 2006. v.2. 585p.

ELLIS, M.A.; MACHADO, C.C.; PRASARTSEE, C.; SINCLAIR, J.B. Occurrence of Diaporthe phaseolorum var. sojae (Phomopsis spp.) in various soybean seedlots. Plant Disease Reporter, v.58, p.173-176, 1974.

ELSTON, R.C. A weight-free index for the purpose of ranking or selection with respect to several traits at a time. Biometrics, v.19, p.85-97, 1963.

GALLI, J.A.; PANIZZI, R. de C.; FESSEL, S.A.; SIMONI, F. de; ITO, M.F. Efeito de Colletotrichum dematium var. truncata e Cercospora kikuchii na germinação de sementes de soja. Revista Brasileira de Sementes, v.27, p.182-187, 2005.

GARCIA, A.A.F. Índice para a seleção de cultivares. 1998. 112p. Tese (Doutorado) - Escola Superior de Agricultura Luiz de Queiroz, Piracicaba.

HAMAWAKI, O.T.; JULIATTI, F.C.; GOMES, G.M.; RODRIGUES, F.A.; SANTOS, V.L.M. Avaliação da qualidade fisiológica e sanitária de sementes de genótipos de soja do ciclo precoce/médio em Uberlândia, Minas Gerais. Fitopatologia Brasileira, v.27, p.201-205, 2002.

LACERDA, A.L.S.; LAZARINI, E.; SÁ, M.E.; VALÉRIO FILHO, W.V. Armazenamento de sementes de soja dessecadas e avaliação da qualidade fisiológica, bioquímica e sanitária. Revista Brasileira de Sementes, v.25, p.97-105, 2003.

MACHADO, J.C.; OLIVEIRA, J.A.; VIEIRA, M.G.G.C.; ALVES, M.C. Inoculação artificial de sementes de soja por fungos, utilizando solução de manitol. Revista Brasileira de Sementes, v.23, p.95-101, 2001.

MENTEN, J.O.M. Prejuízos causados por patógenos associados às sementes. In: MENTEN, J.O.M. (Ed.). Patógenos em sementes: detecção, danos e controle químico. Piracicaba: Fealq, 1991. p.115-136.

MULAMBA, N.N.; MOCK, J.J. Improvement of yield potential of the Eto Blanco maize (Zea mays L.) population by breeding for plant traits. Egyptian Journal of Genetics and Cytology, v.7, p.40-51, 1978.

PASSOS, G.A. Avaliação de caracteres agronômicos e de qualidades fisiológicas e sanitárias das sementes de genótipos de soja [Glycine max (L.) Merril] cultivados em diferentes regiões de Minas Gerais. 1994. 91p. Dissertação (Mestrado) Universidade Federal de Viçosa, Viçosa.

PATRÍCIO, F.R.A.; BORIN, R.B.R.G.; ORTOLANI, D.B. Patógenos associados a sementes que reduzem a germinação e vigor. In: MENTEN, J.O.M. (Ed.). Patógenos em sementes: detecção, danos e controle químico. Piracicaba: Fealq, 1991. p.137-160.

PEREIRA, E.B.C.; PEREIRA, A.V.; FRAGA, A.C. Qualidade de sementes de cultivares precoces de soja produzidas em três épocas. Pesquisa Agropecuária Brasileira, v.35, p.1653-1662, 2000.

PIZZINATTO, M.A.; BOVI, M.L.A.; SOAVE, J.; SPIERING, S.H.; BINOTTI, C.S. Tratamento químico de sementes de pupunheira (Bactris gasipaes): efeitos na sanidade, germinação e vigor. Summa Phytopathologica, v.26, p.42-46, 2000.

SINCLAIR, J.B. Compendiun of soybean diseases. $2^{\text {nd }}$ ed. St. Paul: The American Phytopathological Society, 1982. 104p.

SINCLAIR, J.B. Latent infection of soybean plants and seeds by fungi. Plant Disease, v.75, p.220-224, 1991.

VASCONCELOS, E.S. Avaliação da qualidade de sementes e estimativas de parâmetros genéticos e do padrão de resposta às variações ambientais, em soja [Glycine max (L.) Merrill]. 2006. 142p. Dissertação (Mestrado) - Universidade Federal de Viçosa, Viçosa.

WILLIANS, J.S. The evaluation of a selection index. Biometrics, v.18, p.375-393, 1962.

WRICKE, G.; WEBER, E.W. Quantitative genetics and selection in plant breeding. Berlin: Walter de Gruyter, 1986. 406p.

YORINORI, J.T.; CHARCHAR, M.J.D.; NASSER, L.C.B.; HENNING, L.C.B. Doenças de soja e seu controle. In: ARANTES, E.A.; SOUZA, P.I.M. (Ed.). Cultura da soja nos Cerrados. Piracicaba: Potafos, 1993. p.333-397.

Recebido em 3 de setembro de 2007 e aprovado em 18 de março de 2008 